\title{
A TRAJETÓRIA ESCOLAR DOS ALUNOS DO CURSO DE EDUCAÇÃO FÍSICA: UM ESTUDO DAS FACULDADES INTEGRADAS EINSTEIN DE LIMEIRA
}

\author{
THE STUDENTS ATTENDING THE PHYSICAL EDUCATION DEGREES: A STUDY \\ OF THE FACULDADES INTEGRADAS EINSTEIN OF LIMEIRA
}

\author{
Flávia Baccin FIORANTE ${ }^{1}$ \\ Luci Regina MUZETTI ${ }^{2}$ \\ Cassiano Ferreira INFORSATO ${ }^{3}$
}

RESUMO: O presente trabalho tem como objetivo analisar a trajetória escolar dos alunos e alunas da camada popular do curso de licenciatura em Educação Física das Faculdades Integradas Einstein de Limeira através de uma pesquisa bibliográfica e de campo, esta ultima composta por uma entrevista semi-estruturada. Os dados revelam que, os quatro sujeitos pesquisados, apresentam vários pontos de convergência quanto ao habitus, ao déficit em relação a práticas culturais, à freqüência a eventos esportivos, à empatia com a disciplina Educação Física ao longo do período escolar e à infância regada pela vivência esportiva. Concluímos que esses fatos ajudam a compreender os motivos que podem ter contribuído para a escolha da profissão dos sujeitos pesquisados.

PALAVRAS - CHAVE: Formação profissional. Educação Física. Trajetória escolar.

ABSTRACT: This work aims to evaluate the learning path of the students attending belong to low-income segment in Physical Education teacher degrees in Faculdades Integradas Einstein of Limeira through bibliography and field researches, using a semi structured interview. The results showed that, four of them students show similar answers related to habitus, cultural knowledge deficit, attendance at sporting events, empathy to Physical Education subject during academic life, sport activities during their childhood. We concluded that facts may help understand the professional choice made by the interviewed students.

KEYWORDS: Professional formation. Physical Education. Learning path.

\section{Introdução}

A problemática da formação profissional em Educação Física tem provocado na área, ao longo do tempo, amplas discussões sobre propostas de organização curriculares mais adequadas às novas demandas contemporâneas. Desta forma, as Universidades, centros

\footnotetext{
${ }^{1}$ Faculdades Integradas Einsten (Fiel), Limeira - SP - Brasil. E-mail: flafiorante@uol.com.br.

${ }^{2}$ Universidade Estadual Paulista (Unesp), Faculdade de Ciências e Letras, Araraquara - SP - Brasil. Professora do Departamento de Didática. E-mail: lucirm@fclar.unesp.br.

${ }^{3}$ Universidade Estadual Paulista (Unesp), Faculdade de Ciências e Letras, Araraquara - SP - Brasil. Doutorando no Programa de Pós-graduação em Educação Escolar. E-mail: cassianoferin @ hotmail.com.
}

Doxa: Rev. Bras. Psicol. Educ., Araraquara, v.19, n.1, p. 2-19, jan./jun. 2017. ISSN: 1413-2060 
universitários e as Faculdades, procuram organizar e reorganizar seus currículos de graduação, visando atender as exigências do atual mercado de trabalho, bem como o perfil do aluno que procura cada um dos cursos oferecidos pelas instituições.

O mercado de trabalho é afetado, pois os novos dados e informações são implementados com muita velocidade, sendo cada vez mais perceptível que o conhecimento precisa acompanhar as constantes transformações impostas de modo a garantir que as profissões não sejam extintas frente a estas alterações (FREIRE; VERENGUER; REIS, 2002).

Esta realidade demanda mudanças significativas no contexto escolar que, por conseguinte, refletem na atuação e formação profissional. Com isto, torna-se essencial reconstruir e atualizar a perspectiva que se tem sobre as competências docentes com o propósito de responder aos novos desafios e, assim, formar profissionais capacitados, além de garantir o interesse dos alunos ao ensino superior.

Diante dessas considerações iniciais, ressalta-se que este trabalho é um recorte de uma tese de doutorado, cujo objetivo foi analisar a trajetória escolar dos alunos da camada popular do último semestre do curso de licenciatura em Educação Física das Faculdades Integradas Einstein de Limeira, com o intuito de desvendar as condicionantes que os levaram a optar por esta formação.

Buscou-se, neste estudo, analisar as frações de classes provindas de meios econômicos desfavorecidos, estudando seu histórico familiar, suas práticas, comportamentos, estratégias, expectativas em relação à vida acadêmica, profissional, na tentativa de buscar desvelar, entre outras, os mecanismos que pudessem garantir, ou não, o êxito acadêmico desses estudantes. Tal análise está pautada nos estudos do sociólogo Pierre Bourdieu, pois este referencial permite analisar com rigor as especificidades contidas em uma pesquisa dessa natureza.

\section{Os conceitos presentes na teoria de Pierre Bourdieu: influências significativas nas trajetórias dos alunos do curso de Educação Física}

$\mathrm{Na}$ apropriação do pensamento bourdieuniano encontramos um conjunto de conceitos e categorias capazes de explicar e desmistificar as relações no contexto social e universitário, priorizando os itinerários escolares percorridos pelos universitários (discentes), as estratégias adotadas pelas famílias e pelos próprios estudantes ao longo da trajetória escolar desvelando, em última instância, os mecanismos que influenciam fortemente a "escolha" de um curso, de uma escola e o êxito ou o fracasso dos agentes. Para tanto, elencamos alguns aspectos centrais 
a serem discutidos neste artigo: o conceito de habitus, capital cultural, capital social, capital econômico, estratégias, categorias necessárias para o entendimento das trajetórias escolares dos alunos e alunas do curso Licenciatura em Educação Física.

Bordieu (1974) enfatiza que as perspectivas de uma família em relação à escola dependem também das condições materiais de existência que caracterizam o grupo social ou a fração de classe na estrutura da sociedade, de onde provém as primeiras estruturas formadoras do habitus.

Enquanto força formadora de hábitos, a escola propicia aos que se encontram direta ou indiretamente submetidos à sua influência, não tanto esquemas de pensamentos particulares e particularizados, mas uma disposição geral geradora de esquemas particulares capazes de serem aplicados em campos diferentes do pensamento e da ação, aos quais se pode dar o nome de habitus cultivado. (BOURDIEU, 1974, p.211).

Para tanto, iniciamos com o conceito de habitus, o qual pode ser entendido como

[...] sistemas de disposições duráveis e transferíveis, estruturas estruturantes predispostas a funcionar como princípios geradores e organizantes, isto é, como princípios geradores e organizadores de práticas e de representações que podem ser objetivamente adaptadas a seu fim sem supor a intenção consciente dos fins e o domínio expresso das operações necessárias para atingi-las, objetivamente reguladas e reguladoras, sem ser o produto da ação organizada de um regente. (BOURDIEU, 2003, p.54).

Habitus considerado sistema de disposições duráveis é adquirido através de determinadas atitudes e atos feitos pelo agente social, desta forma, temos o habitus como uma categoria dinâmica que se forma a partir das condições sociais de existência que permeiam a família. A materialização dessas condições, ou seja, conselhos, interditos, preocupações, vivências, experiências, gestos formam as primeiras estruturas do habitus, o qual será reestruturado ao longo da vida.

Para o autor todos os indivíduos possuem um patrimônio que caracterizam as diferentes frações de classes. Tal patrimônio é formado pelo capital cultural, capital econômico e capital social.

O capital cultural esta relacionado com os benefícios que o estudante das diferentes frações de classe podem obter no mercado escolar, ou seja, a obtenção de títulos escolares.

Segundo Bourdieu (1998, p.74, grifo do autor)

O capital cultural pode existir sob três formas: no estado incorporado, ou seja, sob a forma de disposições duráveis do organismo, no estado objetivado, sob a forma de bens culturais - quadros, livros, dicionários, 
instrumentos, máquinas, que constituem indícios ou a realização de teorias ou de críticas dessa teorias, de problemáticas, etc; e enfim no estado institucionalizado, forma de objetivação que é preciso colocar à parte porque, como se observa em relação ao certificado escolar depende do capital social - também herdado - que pode ser colocado a seu serviço.

O capital econômico é representado pela apropriação de bens materiais, já o capital social está intimamente relacionado com as relações humanas que constituem fontes importantes para a atuação e manutenção dos agentes sociais em determinadas frações de classe.

O epicentro da nossa discussão encontra-se na possibilidade de que o rendimento e o êxito escolar dependem do capital cultural e econômico investido pela família e que também o rendimento social e econômico deste investimento esta associado à herança social e ao capital simbólico que esta à disposição.

Bourdieu ressalta ainda que seja necessário entendermos as estratégias que estão intimamente relacionadas com os investimentos educativos. Encontramos nos estudos de Muzzeti (1997) a classificação das estratégias:

a) estratégias de fecundidade visam diminuir os pretendentes ao patrimônio da família, limitando o número de descendentes.

b) estratégias sucessoriais, fundadas no costume e no direito, têm por objetivo transmitir o patrimônio da família para seus descendentes com o mínimo de desperdício, inclui desde a compra de quadros até os mais variados bens;

c) estratégias culturais incluem a transmissão do capital cultural pela família, o investimento escolar e as atividades extra-escolares;

d) estratégias profiláticas visam à manutenção da saúde dos agentes pertencentes ao grupo;

e) estratégias econômicas, que incluem as operações de crédito, poupança e os investimentos econômicos em geral;

f) estratégias de investimento social visam a garantir ao grupo relações sociais duráveis, mobilizáveis e úteis, funcionam como ponto de apoio entre os agentes, e incluem, entre outras coisas, o sentimento de respeito entre eles;

g) estratégias matrimoniais visam à reprodução biológica do grupo por meio do casamento.

h) estratégias ideológicas, que visam a naturalizar os privilégios, ou seja, transformar as diferenças sociais em diferenças naturais, legitimando a dominação.

Vale frisar que Bourdieu salienta em suas obras que existe uma íntima relação e interdependência entre as estratégias, como, por exemplo, entre as estratégias econômicas e as culturais, ou seja, quanto maior o valor atribuído ao capital cultural, materializado muitas vezes na importância dada aos estudos, maior tende a ser a propensão a investir economicamente em práticas culturais, tais como, cursos de línguas estrangeiras, e outras atividades extra-escolares. 


\section{O percurso metodológico}

O método utilizado neste trabalho foi o praxiológico bourdiano presente nos estudos do sociológico Pierre Bourdieu, através de uma pesquisa bibliográfica e de campo, esta composta de uma entrevista semi-estruturada (LUDKE; ANDRÉ, 1986).

A investigação foi realizada nas Faculdades Integradas Einstein de Limeira - FIEL, localizada na cidade de Limeira, interior do estado de São Paulo, com os alunos e alunas provenientes da camada popular do último semestre do ano de 2010 do curso de licenciatura em Educação Física.

Foram entrevistados quatro alunos do sexo masculino, escolhidos aleatoriamente, e que concordaram em participar da pesquisa através da assinatura do Termo de Compromisso Livre e Esclarecido. Vale frisar que a escolha por quatro alunos, deveu-se ao fato de ter sido constatado, no referencial teórico de Bourdieu, que agentes sociais provenientes de uma mesma fração de classe, tendo às mesmas condições materiais de existência e sujeitos as mesmas ações práticas, tendem a ter a homogeneização de seu habitus, podendo haver semelhanças nos discursos. Portanto, a regularidade das disposições encontradas neste estudo, levou-nos a acreditar que os dados obtidos se ratificam e tendem a ser relevantes em outras instituições de ensino superior que possuírem características semelhantes.

O roteiro das perguntas foi realizado em função das categorias de análise, ou seja, habitus, capital cultural, capital social e capital econômico, estratégias, pautadas nos estudos de Boudieu, e também nos trabalhos de Portes (1993), Barbosa (2004), Lacerda (2006), Almeida (2006) e Piotto (2007), os quais ressaltaram a trajetória escolar de alunos das camadas populares que tiveram acesso a diferentes cursos superiores de alta seletividade em Universidades consideradas centros de excelência. Vale frisar, que tais trabalhos fundamentaram-se no modelo teórico do mesmo autor evidenciado neste trabalho, ou seja, Pierre Bourdieu.

Para melhor compreensão da análise, separamos os resultados obtidos na entrevista nos seguintes subtópicos: família, relação família-escola, escola e formação profissional.

\section{Análise da trajetória escolar dos alunos do curso de Educação Física}

Todos os alunos entrevistados são provindos da camada popular, filhos de trabalhadores braçais. Para preservar suas identidades, utilizaremos números para identificá- 
los. A partir das entrevistas, constatamos que eles possuem entre vinte e trinta e um anos. Apenas um é casado, possui um filho de dois anos e a esposa é Pedagoga.

\section{Família}

Todas as famílias são provindas dos meios urbanos e residem em áreas com renda familiar inferior ou de até três salários mínimos, conforme dados fornecidos pelo Plano Diretor da Cidade de Limeira (LIMEIRA, 2010).

O nível de escolarização alcançado pelos chefes de família, representados pelo pai, indicou que dois eram inferiores aos da mãe. Duas possuíam ensino médio, antigo colegial, e os demais cursaram, assim como as mães, no máximo até o $6^{\circ}$. ano do atual ensino fundamental. Esse dado evidencia a existência de um distanciamento com o sistema de ensino. Desta forma, segundo Bourdieu, a herança cultural proveniente do meio familiar pelos pais e pelos avós, no que se refere à ascensão social através da longevidade escolar, foi prejudicada.

A média das taxas de fecundidade dessas famílias corresponde a três filhos, sendo apenas um deles filho único.

Quanto aos investimentos escolares, os três alunos tem dois irmãos mais velhos, sendo que cada um deles tem um irmão que concluiu o ensino médio. De um dos entrevistados, as irmãs cursaram apenas o ensino fundamental.

Observamos que, em duas famílias, o nível escolar alcançado pela prole está diretamente relacionado com a taxa de fecundidade da família e com o lugar alcançado na fatria, ou seja, em média três filhos e um capital econômico que não é suficiente para investir na escolarização de todos os filhos. Desta forma, apenas o filho caçula deu prosseguimento aos estudos até o ensino superior.

No que se refere ao capital social dessa fração de classe, pudemos verificar que o círculo de amigos que freqüentavam a casa dessas famílias eram pessoas da mesma fração de classe. Dois alunos citaram que recebiam amigos da igreja.

Andava muito com o pessoal da igreja, do mesmo nível que eu. Sempre que saia da igreja ou o pessoal passava na minha casa ou na casa dos amigos para comer alguma coisa, era um nível quase que parecido. (Aluno 3)

$\mathrm{Ou}$ 
Com esses depoimentos, podemos concluir que o capital social dessas famílias constituíram-se na infância, por meio das relações feitas na igreja que freqüentavam. Para Bourdieu o capital social é formado pelas relações humanas, vinculação a um determinado grupo. No caso dessas famílias, o vínculo era a igreja evangélica.

O depoimento do aluno 3, ou seja, a declaração de que: "Andava muito com o pessoal da igreja, do mesmo nível que eu”, ratifica, mais uma vez, a fala de Bourdieu quando se pronuncia dizendo que as primeiras experiências socializadas no seio familiar estão relacionadas com a condição de classe a qual pertence a família. Tal condição é que estrutura o habitus.

Para Bourdieu (2003, p.71), portanto, o habitus é considerado como:

[...] sistema subjetivo, mas não individual, de estruturas interiorizadas, esquemas e percepção, de concepção e de ação, comuns a todos os membros do mesmo grupo ou classe e constituintes da condição de toda objetivação e percepção, baseamos a articulação objetiva das práticas e a unicidade da visão do mundo na impessoalidade e a substituibilidade perfeita das práticas e das visões singulares.

Das outras duas famílias, uma não costumava receber amigos em casa e a outra recebia poucos, conforme afirmou o aluno 4:

Recebia poucos, era os colegas do meu pai que trabalhava na metalúrgica que passava em casa.

Em relação às práticas culturais, ou seja, visita a museus, bibliotecas e cinemas, notamos, de acordo com os depoimentos dos sujeitos pesquisados, que não eram comuns nessas famílias como mostra os dizeres do Aluno 2:

Passava as férias na casa de minha avó em Ouro Verde.

Eu freqüentava biblioteca só para fazer trabalhos da escola, livraria e museu não ia, e cinema só depois dos dez anos". (Aluno 3)

Eu passava as férias na casa de parentes fora de Limeira. No cinema fui para ver filmes da Xuxa. Museu fui no de Limeira e em Rio Claro com a Escola. (Aluno 4)

Nunca tive acesso a museus, livrarias, biblioteca, só cinema de vez em quando. (Aluno 5) 
A fala do aluno 4, ou seja, "Museu fui no de Limeira e em Rio Claro com a Escola", nos leva a crer que para essa fração de classe o acesso a práticas culturais depende da instituição escolar. Para Bourdieu essa fração de classe vê, na escola, a única possibilidade de ascensão social, e por isso, deposita, nessa instituição, o futuro de seus filhos. O mesmo autor ressalta também que os agentes pertencentes a essa fração de classe, por possuírem um baixo patrimônio herdado pela família, tendem a substituir as práticas culturais pelas necessidades da vida diária, como moradia, alimentação, saúde. Desta forma, tais práticas não fazem parte da herança cultural herdada no seio familiar.

Embora não participassem de eventos culturais, todos os entrevistados declararam participar de eventos esportivos, tais como jogo de futebol e outras modalidades coletivas, bem como de projetos esportivos.

Participei de projetos de futebol, futsal e tênis de mesa. (Aluno 2)

No Sesi, participava do projeto de futebol. (Aluno 3)

Essa ocorrência deve-se, provavelmente, ao fato dessas famílias não possuírem os códigos simbólicos necessários para decifrar essas práticas culturais. Para Bourdieu (2003), existe uma íntima relação entre o nível de instrução da família e a disposição em consumir os bens simbólicos como leitura, música etc. Em outros termos, para consumi-los é preciso que o agente, ou o grupo de agentes, possua os códigos necessários para entendê-los, conforme já expresso. Além disso, no caso de viagens, visitas a museus, teatros e concertos, a família deve possuir também capital econômico para poder arcar com as despesas necessárias.

Vale destacar que o volume de privilégios culturais e a escolha por determinadas práticas, como por exemplo, a escolha dos esportes, dos tipos de músicas, estão relacionadas com a origem social dos agentes. Bourdieu (2003) destaca também que é comum os agentes sociais pertencentes a camada popular ou média baixa assistirem a transmissões esportivas. Provavelmente essa preferência ocorra pelo fato de terem apenas códigos simbólicos necessários para decifrar este tipo de prática cultural.

Os gostos, costumes, escolhas, preferências enraizados no seu habitus primário, em relação à disciplina e Educação Física, começa a se estruturar por meio das condições matérias de existência de sua família e também pelo acesso a essas práticas culturais.

\section{Relação família- escola}


No que diz respeito à relação que essas famílias mantinham com a instituição escolar, a maioria ressaltou que a família participava da vida escolar, destacado nos seguintes depoimentos:

\section{Minha mãe participava mais. (Aluno 2) \\ Minha família participava bastante. (Aluno 3)}

Ah! Nunca deixaram de ir em reuniões, quando eu aprontava na escola pegava no meu pé. (Aluno 5)

Apenas um aluno se pronunciou dizendo que a família não tinha nenhuma expectativa em relação à escola:

Minha família não tinha expectativa nenhuma em relação à escola. (Aluno 2)

Pudemos também notar que esse grupo social mantinha contato freqüente com professores, participavam de reuniões, conferiam as tarefas escolares, incentivavam os estudos, mantinham boas relações com os professores. Desta forma, fica possível considerar que o estudo fazia parte do habitus familiar. Vale frisar que todos estudaram em escola pública, devido à condição econômica da família e da fração de classe a qual essas famílias pertencem.

\section{Minha mãe incentivava os estudos e conferia minha tarefa. (Aluno 2)}

Eles olhavam as tarefas, se estivesse errado eles perguntavam se eu não queria fazer mais uma vez. (Aluno 3)

Meus pai incentivavam os estudos, só que como sempre fui bom aluno e era elogiado nas reuniões, eles deixavam de lado. (Aluno 4)

Ah nunca deixou de ir em reuniões, quando eu aprontava na escola pegava no meu pé. Meus pais apoiavam sempre porque eu sempre estudei em uma escola pública muito boa aqui de Limeira e era bem rígida e eu fui um aluno que sempre deu muito trabalho, eles estavam de acordo e brigavam bastante comigo. Porque eles queriam o meu bem. Queria que eu tivesse disciplina na escola e aproveitasse tudo de bom que a escola oferece, pois tem coisa que a escola oferece e eles não podiam dar. Eles sempre me apoiaram nos estudos, meus irmãos também, minha irmã se empenhou mais que eu na escola eu acho, participou, sempre foi boa aluna, como se fala, que participou dos projetos da escola e tal. (Aluno 5)

Notamos uma nítida convergência com os estudos de Lacerda (2006) e Almeida (2006), os quais ressaltaram que a mobilização familiar é extremamente necessária para a 
longevidade escolar dos filhos. Completam ainda, que esta mobilização se materializa, sobretudo na figura da mãe, as quais acabam empreendendo uma série de estratégias para contribuir com o sucesso escolar, entre elas: contatos freqüentes com a escola, vigilância da vida escolar, tanto no se que refere a ordem moral como também para incutir nos filhos a importância e a necessidade dos estudos.

Já os trabalhos de Portes (1993) e Piotto (2007) evidenciaram que as famílias apresentaram formas menos visíveis na escolarização dos filhos, ou seja, não havia esforços específicos direcionados a escola, refletindo desta forma, em uma presença quase nula dos familiares na longevidade escolar dos filhos. Em tais pesquisas, não foram relatadas estratégias educativas ou práticas culturais visando o incentivo no percurso escolar dos alunos investigados.

\section{Escola}

As famílias pesquisadas neste trabalho consideram a escola como uma via de acesso à ascensão social. Vislumbrando nela a única forma de ter uma formação para obter um futuro diferente daquele que tiveram os seus pais.

Os estudos de Lacerda (2006) e Almeida (2006) revelaram que as famílias pesquisadas atribuíram a escola, a possibilidade de ultrapassar a condição social dos pais.

Para Bourdieu (1998), os filhos das classes menos favorecidas recebem, da família, uma espécie de boa vontade cultural vazia, e são forçados a tudo esperar, a tudo receber da escola. O motivo é que os pais pouco podem fazer para garantir o sucesso no interior da escola, pois não possuem um patrimônio cultural suficiente para transmitir os valores impostos e legitimados pelo sistema escola.

Através do depoimento do aluno 5 observamos a preocupação dos pais com a disciplina, dedicação aos estudos, devido à instrução dada ao filho, para que ele aproveite tudo de bom que a escola oferece. Entendemos que esse "tudo de bom" como as práticas culturais pedagógicas, planejadas, organizadas e praticadas na escola. O conteúdo dessa parte da entrevista comprova uma disposição ascética dessa família em relação ao sucesso escolar, expressa através de orientações, conselhos, apoio aos estudos, o que resultou em uma possível ascensão social via escola.

A escola é a base de tudo. Acho que eles pensavam assim porque não queriam que eu passasse a mesma coisa que eles passam hoje. (Aluno 3) 
Minha família pensava na escola como uma maneira de aprender a ler e escrever para ser alguém na vida. Acredito que eles tinham esse tipo de comportamento, pelo fato do meu pai ser metalúrgico, um serviço sujo, pesado ele pensava que tinha que estudar para não enfrentar isso na vida.

Bourdieu (2003) é da opinião de que o êxito escolar está relacionado com o capital cultural acumulado no seio familiar. Sendo assim, esperávamos que a trajetória escolar da maioria desses alunos fosse marcada por atrasos, reprovações. No entanto, notamos que apenas dois deles sofreram reprovação ao longo do percurso escolar.

Bom eu reprovei quando mudei de escola quando eu sai da oitava série e fui para o primeiro colegial, eu não me adaptei na escola nova, eu não gostava de ir naquela escola daí ao invés de eu faltar eu preferia enforcar aula ou não assistir a aula, então reprovei. Quando reprovei cheguei lá na boa e ele me perguntou o que tava acontecendo, ai eu expliquei que eu não gostei e tal, ai ele me mudou de escola, daí que eu mudei para um colégio particular. (Aluno 3)

Eu reprovei um ano por falta, foi bem difícil, meu pai e minha mãe ficaram tristes e deu uns castigos, mas eu superei. (Aluno 3)

Já os outros dois salientaram o fato de serem sempre elogiados pelos professores.

Nunca tive problema com reprovação, já que eu sempre quis ser um bom aluno, eu chegava chorando em casa se tirasse um $B$, tudo isso por conta própria, eles nunca ficaram em cima. (Aluno 4)

Os professores sempre me elogiaram. (Aluno 5)

Neste depoimento, notamos uma adesão aos valores escolares, como exemplo: tirar notas boas, ter um bom comportamento, o que, segundo Bourdieu pode refletir em uma ascensão social.

Piotto (2007) detectou em seu estudo a influência e a importância do professor reconhecer o bom desempenho escolar, bem como estimular e fornecer informações sobre o sistema de ensino. Convergindo com nosso estudo, é possível verificar que a figura do professor, ou seja, o seu comportamento, os conselhos, as recomendações feitas, contribuem para a ascensão escolar de alguns dos nossos sujeitos pesquisados.

Eu tinha bastante conversa com os professores, acabava a aula a gente ficava conversando com eles. Eles falavam sobre a importância de estudar. (Aluno 4) 
Ah, eu sempre respeitei o professor, eu era bagunceiro tinha problema com os alunos, gostava de aparecer um pouco, mas com o professor eu sempre tive uma boa relação. Eles davam conselhos, conversavam numa boa, falavam da importância de ir bem na escola para ser alguém na vida. (Aluno 5)

Mesmo tendo o professor uma participação importante no percurso escolar, coube à família a orientação da escolha profissional, mesmo tendo pouco capital cultural, devido às condições materiais de existência. Verificamos, pelo conteúdo das entrevistas, que coube aos pais a explicação sobre o sistema de ensino e sobre as profissões mais rentáveis.

Meus pais falavam para pesquisar bastante, antes de escolher uma profissão. (Aluno 3)

Meus pais explicavam sobre o sistema de ensino, como era as profissões que davam mais dinheiro. (Aluno 5)

Apesar dos familiares terem um nível de escolaridade baixo e estarem distantes do sistema de ensino notamos que havia, neles, a preocupação com a escolha da profissão, com a rentabilidade destas no mercado. Tais atitudes, mesmo que de maneira inconsciente, contribuíram para que fossem formadas disposições que passariam a ser arraigadas no habitus.

Já os outros dois alunos citaram que os pais nunca tiveram este tipo de conversa, talvez por acreditarem que tal função cabia à escola e também por não possuírem capital cultural suficiente para dar esse tipo de conselho e informação.

Em relação aos questionamentos voltados à disciplina Educação Física, notamos que todos os alunos participavam das aulas, quando crianças e adolescentes, e que o conteúdo preferido era o esporte, em especial as modalidades coletivas. Isso pode ser observado nos seguintes depoimentos:

Eu gostava muito de fazer futsal. (Aluno 2)

Eu gostava de quase tudo, mas preferia o futebol. (Aluno 3)

Vôlei (Alunos 4)

Eu gostava de fazer esporte: futebol e vôlei. (Aluno 5)

Acreditamos que essa relação com o exercício físico vem das disposições assimiladas desde a infância, como as brincadeiras vivenciadas na rua, além da frequência a eventos esportivos. 
Quando criança a gente brincava na rua de futebol. (Aluno 2)

Além de polícia e ladrão, pega-pega, esconde-esconde, brincava todo mundo junto de futebol. (Aluno 3)

Eu gostava de soltar pipa, bicicleta e jogar bola e vôlei. (Aluno 5)

Nestes depoimentos ficou claro que esses alunos tiveram, em seu habitus primário, a incorporação de um capital esportivo que garantiu uma aproximação com os conteúdos da disciplina Educação Física, em especial o esporte. Todos afirmaram ter um rendimento bom nas aulas de Educação Física e destacaram a figura do professor, declarando que eram bons profissionais. Esse posicionamento por parte dos alunos nos leva a pensar que essas experiências positivas com a área contribuíram para a escolha da profissão e, especialmente, pela licenciatura. Vale destacar que, dos quatro alunos, dois foram atletas de futebol e todos escolheram o curso de Educação Física (licenciatura) como primeira opção. Eles se expressam assim sobre esse assunto:

Não tive, professor ruim, não tive nenhum que jogava a bola. (Aluno 2)

Da primeira a oitava série o professor deu a base para a gente, o que é muito raro ver hoje, ele passava primeiro a aula em vídeo com regras, como jogava e depois ia para a prática, hoje é o contrário, já vai para a prática direto. Sempre tem uma turminha que se dá melhor por já estar dentro do esporte, e como eu já fazia escolinha de futebol eu me sobressaia nas aulas. (Aluno 3)

Eu gostava muito, muito do meu professor. (Aluno 4)

Meu professor, eu tive vários, os últimos foram os melhores. Meu rendimento nas aulas Educação Física sempre foi melhor que nas outras disciplinas. (Aluno 5)

\section{Formação profissional}

Quando questionados sobre os motivos que os levou a ingressar no ensino superior, todos se pronunciaram dizendo que a escolha esteve relacionada com a possibilidade de alcançarem um emprego melhor, como diz Aluno 3

Bom, hoje em dia, sem estudo não leva a nada, optei por ter uma formação acadêmica para ter um emprego melhor. (Aluno 3) 
Aumentar o nível, ter uma vida melhor, uma profissão. (Aluno 4)

Segundo os estudos de Barbosa (2004), Lacerda (2006) e Piotto (2007) o ingresso no ensino superior e a experiência vivenciada ao logo do curso refletem como uma abertura para novas possibilidades tanto de ordem pessoal, familiar e financeira. Barbosa (2004) reforça ainda, que tal acesso contribui também para iniciar e/ou ampliar o capital cultural e social.

Sobre a escolha pela licenciatura, os alunos responderam:

Tenho um sonho de ser efetivo no estado. (Aluno 2)

Eu escolhi a licenciatura por causa que eu já jogava futebol, já foi um caminho, eu sempre gostei de esporte e desde pequeno eu dizia que ia ser professor de Educação Física. (Aluno 3)

Quero a licenciatura para tentar dar um jeito nessa criançada. (Aluno 4)

Escolhi a licenciatura por gostar muito de esporte. (Aluno 5)

O depoimento do aluno 2 ratifica mais uma vez a fala de Bourdieu quando cita que cada agente tende a viver de acordo com sua condição material de existência, não almejando o impossível, sendo assim, por possuir um capital social e econômico reduzido, provavelmente não conseguirá lecionar em escolas particulares, restando a opção de estudar e passar em um concurso, sendo professor efetivo de estado.

O mesmo autor ainda enfatiza que uma parte do mercado de trabalho esta reservada, por direito, e ocupada, de fato, pelos detentores, ou seja, pelos agentes provenientes das camadas favorecidas.

A escolha da profissão não estava de acordo com os anseios da família, segundo três alunos:

Não era pretensão da minha mãe que eu fizesse Educação Física. (Aluno 2)

Meu pai queria que eu fosse engenheiro. (Aluno 3)

Não estava de acordo com a vontade da minha família. (Aluno 5)

Já para o aluno 4:

Meus pais são muito orgulhosos por ter um filho que faz Educação Física. (Aluno 5) 
Em suma, em relação à trajetória escolar desses alunos temos elementos para afirmar que o patrimônio herdado pela família não garantiu o acesso a práticas culturais, o que refletiu em um empobrecimento do capital cultural quando freqüentaram a escola. Porém, notamos ter existido uma dedicação, um esforço e uma preocupação por parte da família em reforçar o que era preconizado pela escola, além da figura do professor de Educação Física, o qual dava conselhos, tinha boa atitude profissional. Essas atitudes contribuíram para que os alunos passassem a ter afinidade com essa disciplina.

\section{Considerações finais}

Discorrer sobre a trajetória escolar de alunos e alunas do curso de licenciatura em Educação Física das Faculdades Integradas Einstein de Limeira remete-nos a algumas reflexões, inquietações e considerações sobre a temática.

Mais uma vez ressaltamos que, todos os alunos pesquisados são provenientes de camada popular. Reforçamos desta maneira que, no referencial teórico oferecido por Bourdieu, fica evidente que agentes sociais, provenientes de uma mesma fração de classe, tendo as mesmas condições materiais de existência e sendo sujeitos às mesmas ações práticas, tendem a ter a homogeneização de seu habitus. Nesse sentido, a regularidade das disposições encontradas neste trabalho, indica que tais informações tendem a ser importantes em outras instituições de ensino superior que possuam características iguais ou semelhantes.

No que se refere à família, mais especificamente ao nível de escolarização alcançados pelos chefes, todos cursaram até, no máximo, o $6^{\circ}$. ano do atual ensino fundamental, o que evidencia um distanciamento com o sistema de ensino, comprometendo a herança familiar em relação à ascensão escolar. Todos os entrevistados são conscientes desta distância, e por tal motivo citaram que o estudo pode levá-los a ter uma condição melhor, um emprego digno.

Em relação ao capital social, verificamos um déficit significativo em todos os alunos. Também percebemos que frequiência às práticas culturais não eram comuns nessas famílias, o que tende a contribuir para um reduzido capital cultural. Acreditamos que isso esteja relacionado às condições materiais de existência, à origem social dos agentes, nível de instrução das famílias e ao fato da cidade de Limeira não possuir um entorno cultural que facilitasse o acesso dessas pessoas a ele. Aliado a essas questões, a fala da maioria dos sujeitos evidencia que cabe à escola o acesso às práticas culturais, ou seja, o meio escolar é a forma certificada e garantida de adquirir o capital cultural. 
Já o acesso a práticas esportivas também foi evidenciado por todos os alunos, os quais freqüentavam clubes, jogos esportivos, projetos envolvendo várias modalidades, seja por terem sido atletas ou pela empatia com o esporte e também por possuírem as disposições e os códigos necessários para interpretar práticas dessa natureza.

Constatamos também, uma nítida semelhança, não só no patrimônio herdado pela família, mas também em seus habitus, todos tiveram uma infância regada à vivência esportiva, seja como atletas, seja como expectador de jogos esportivos, o que tende a ter contribuído para despertar na infância, o habitus esportivo. Esse habitus foi cultivado na adolescência e contribuiu, de maneira significativa, para a escolha da profissão.

No tocante relação família-escola, a maioria dos alunos, salientaram que seus pais participavam da vida escolar, mantinham contato com os professores, freqüentavam reuniões, verificavam as tarefas escolares. Essas ações mostram que tais famílias viam na escola a possibilidade de uma ascensão social, para que seus filhos tivessem, dessa maneira, um futuro diferente dos pais.

Notamos que na escola, acontecia visivelmente a empatia com a disciplina Educação Física, a preferência pelo esporte enraizados no habitus primário de todos os sujeitos da pesquisa começaram a se estruturar por meio das condições materiais de existência das famílias, às quais cada um deles pertence. Isso ocorreu devido às disposições assimiladas na infância, como as brincadeiras vivenciadas na rua e também pelo acesso a práticas culturais de cunho esportivo.

No que se refere às informações sobre a formação profissional, salientamos que a ampliação das faculdades e centros universitários na região de Limeira, permitiu o acesso ao ensino superior, possibilitando a presença da camada popular neste nível de escolarização, contribuindo para que esta fração de classe não dependa exclusivamente do sistema público para se beneficiar no processo escolar e por meio deste, aumentar suas reais chances de inserção no mercado de trabalho.

O fato de Limeira ter também o curso de Ciência do Esporte na Unicamp, não faz com que as Faculdades Integradas Einstein de Limeira seja prejudicada, em termos de procura pelo curso de Educação Física. Os estudantes dessa última Instituição de Ensino Superior, de acordo com os dados da pesquisa, se revelaram: deficitário em termos de capital cultural e de patrimônio herdado pela família. E assim, mesmo que todos tenham apresentado um significativo habitus esportivo, esse fato tende a não ser suficiente para poderem almejar uma vaga em uma Instituição Pública de Ensino Superior. Mesmo porque, o ingresso a 
Universidade pública, principalmente centros de excelência, tendem a ser feitos por estudantes de camadas sociais favorecidas.

Por fim, almejamos que esse estudo possa contribuir para que novas reflexões aconteçam em torno da temática em pauta, e que ao ser identificada a trajetória desses alunos e alunas do curso de Educação Física da instituição em questão, desvelando entre outras, o perfil do discente que frequenta este curso, tais informações possam contribuir para que possíveis "arestas" do projeto pedagógico sejam (re) avaliadas não só pelo Conselho de Curso, juntamente com a coordenação, mas também pela instituição como um todo. Também apontamos a necessidade de novas investigações sobre a participação e influência da família e da escola na escolha da profissão de alunos das diferentes camadas sociais.

\section{REFERÊNCIAS}

ALMEIDA, W. A. Esforço contínuo: estudantes com desvantagens socioeconômicas e educacionais na USP. 2006. 136f. Dissertação (Mestrado em Sociologia). Faculdade de Filosofia, Letras e Ciências Humanas, Universidade de São Paulo, São Paulo, 2006.

BARBOSA, M. A. Estudantes de classes pobres na universidade pública: um estudo de depoimentos em psicologia social. 2004. Dissertação (Mestrado em Psicologia). Instituto de Psicologia, Universidade de São Paulo, São Paulo, 2004.

BOURDIEU, P. O esboço de uma teoria da prática. In: ORTIZ, R. (Org.). A sociologia de Pierre Bourdieu. São Paulo: Olho D’ Água, 2003. p.39-72.

BOURDIEU, P. As contribuições da herança. In: NOGUEIRA, M. A.; CATANI, A.(Org.). Escritos de Educação. Rio de Janeiro: Vozes, 1998. p.229-237.

BOURDIEU, P. A Economia das trocas simbólicas. São Paulo: Perspectiva, 1974.

FREIRE, E. S.; VERENGUER, R. C. G.; REIS, M. C. C. Educação Física: pensando a profissão e a preparação profissional. Revista Mackenzie de Educação Fisica e Esporte, São Paulo, v.1, n.1, p.39-46, 2002.

LACERDA, M. G. Famílias e filhos na construção de trajetórias pouco prováveis: o caso dos iteanos. 2006. 417f. Tese (Doutorado em Educação). Faculdade de Educação, Universidade Federal Fluminense, Niterói, 2006.

LIMEIRA. Prefeitura Municipal. Plano Diretor. Limeira: Secretaria de Planejamento e Urbanismo, 2010.

LUDKE, M.; ANDRÉ, M. E. D. A. Pesquisa em educação: abordagens qualitativas. São Paulo: EPU, 1986. 
MUZZETI, L. R. Trajetória social, dote escolar e mercado matrimonial: um estudo de normalistas formadas em São Carlos nos anos 40, São Carlos, UFSCar. 1997. 174f. Tese (Doutorado em Educação) - Universidade Federal de São Carlos, São Carlos, 1997.

PIOTTO, D. C. As exceções e suas regras: estudantes das camadas populares em uma universidade pública. 2007. 361f. Tese (Doutorado em psicologia) - Instituto de Psicologia, Universidade de São Paulo, São Paulo, 2007.

PORTES, É. A. Trajetórias e estratégias do universitário das camadas populares. 1993. 248f. Dissertação (Mestrado) - Faculdade de Educação, Universidade Federal de Minas Gerais, Belo Horizonte, 1993.

\section{Como referenciar este artigo}

FIORANTE, Flávia Baccin.; MUZETTI, Luci Regina.; INFORSATO, Cassiano Ferreira. A trajetória escolar dos alunos do curso de educação física: um estudo das Faculdades Integradas Einstein de Limeira. Doxa: Rev. Bras. Psicol. Educ., Araraquara, v.19, n.1, p. 219, jan./ jun. 2017. ISSN: 1413-2060.

Submetido em: 01/01/2017

Aprovado em: 30/03/2017 